\title{
COMPREHENSIVENESS AND EFFECTIVENESS: STRATEGY EXECUTION IN CORPORATE HEADQUARTERS
}

The purpose of this paper is to examine the relationship between the comprehensiveness of implementation activities and the effectiveness of the execution of corporate headquarters strategy. The comprehensiveness was defined by means of three areas: procedures and processes, cohesion of corporate values, and implementation tools, whereas the effectiveness of strategy implementation was expressed through the effectivity of strategic objectives realization, as well as eliminating internal and external implementation barriers. The studies were carried out across 69 corporate headquarters. The research proved the existence of a positive relationship between the examined areas, thus the comprehensiveness of strategy execution increases the effectiveness of the undertaken activities. This means that in order to provide a high execution level of a designed strategy, it is advisable to organize the process in a well-thought-out, systematic, and cohesive way.

Keywords: strategy execution, comprehensiveness, implementation, effectiveness

DOI: 10.15611 aoe.2016.2.09

\section{INTRODUCTION}

Strategy execution falls within the purview of many kinds of studies and analyses, since the percentage of successfully implemented strategies remains unsatisfactory (Bossidy, Charan, 2002; Hrebiniak, 2006). Therefore it is appropriate to carry out research on the comprehensiveness of this process. The subject is significant especially in the context of the methods in which headquarters use execution programs for advancing their strategies. In particular it is worth examining the comprehensiveness and effects they bring. As argued by Fredrickson and Mitchell (1984), it is a measure of rationality, and should be analysed as a process of integrating various aspects into an overall strategy.

The objective of this work is the analysis of the relationships between the comprehensiveness of implementation activities and the effectiveness of the execution of the corporate headquarters' strategy. An answer has been sought to the question of whether ensuring a higher degree of

* Wrocław University of Economics 
comprehensiveness of the undertaken proceedings enhances the effectiveness in strategy execution.

Comprehensiveness was here defined by the following terms: processes, corporate values cohesion, and the tools used. The effectiveness in strategy execution was expressed as the efficacy of the strategic objectives achievement as well as the elimination of internal and external barriers. Sixty nine corporate headquarters were studied.

\section{LITERATURE REVIEW AND HYPOTHESES}

As the results of many studies imply, in spite of creating more advanced models and support schemes, strategy realization is a particularly crucial and most difficult stage of strategic management processes (Beer, Nohria, 2000; Raps, 2004; Carlopio, Harvey, 2012). This is due to the inability of managers to comprehensively perceive this multidimensional sequence of actions combining various elements including, but not limited to, systems, resources, and structure (Higgins, 2005). Other approaches also draw attention to aspects of communication (Schaap, 2006), and to the necessity of ensuring internal consensus (Rapert et al., 2000) or appropriate coordination (Hrebiniak, 2008). The concepts of creating socialpsychological models of strategic implementation processes in which the participation of groups and individual employees are emphasized, may not be disregarded (Carlopio, Harvey, 2012). The strategy implementation process is especially complicated in the case of complex-structure organizations where separate strategies are often carried out by business units. Coordination and actions undertaken in order to ensure cohesion on various levels of the strategy implemented is therefore an additional role performed at corporate headquarters. The analysis of the literature on strategy implementation showed that the comprehensiveness of this process is defined in the following three aspects.

The first one is defined as processes and procedures. Coon and Wolf (2005), draw attention to the importance of aligning processes and systems to reinforce desired behaviors and outcomes. Ensuring the efficient and coherent functioning of the three processes in a company is of high significance in this area. The first of these is the decision-making process, within the scope of which it is essential to provide decision-making powers and facilitate the transfer of responsibility for implementing measures (Mezger, Violani, 2011). The second is the coordination of resources and fulfillment of aims in accordance with the given intentions (Hao, Kasper, 
Muehlbacher, 2012). The third process concerns aligning the organizational structure, which is improving strategy implementation (Gibbs, 2005), and providing a support system for managers during the execution of strategic goals (Robbin, DeCenzo, 2005).

The second investigated aspect relates to implementing tools, since their influence on the effectiveness of the implementation process is emphasized by a great many authors (Dandira, 2011; Ramsey, 2010). It is essential to create a system of results measurement which has a positive impact on the level of a developed strategy execution (Sharma et al., 2005). It is indicated that tools such as BSC (Thompson, Mathys, 2008) and strategy maps (Free, $\mathrm{Qu}, 2011)$ are most commonly used. They are often deployed simultaneously which promotes synergy by indicating mutual relations and casual relationships between their constituent parts (Bourguigon et al., 2004). This in turn translates into a higher degree of aligning manager's perception (González et al., 2012) and a reduction in information load (Cheng, Humphreys, 2012). Other tools, such as budgeting and scheduling, are also used while implementing the strategy. These promote appropriate resource allocation as well as identifying key performance indicators (Saunders, Mann, 2008).

The last analysed aspect was defined as the coherence of corporate values. Thist includes various managers' activities undertaken in order to ensure the multidimensional coherence of the organization. This in turn influences the degree to which the strategy is executed (Bertrand, Schoar, 2003; Judge, Piccolo, 2004). O'Reilly et al. (2009) emphasize that the key factor in a successful change introduction is ensuring the alignment of leadership across hierarchical levels. This is undoubtedly aimed at increasing the employees' engagement in the implementation stage, in particular this consists in cooperating multitasking teams. One of the aspects serving this is the communication of a common vision of company development, as well as a coherent set of values. As the research results indicate, streamlining the internal communication process itself appears to be of key importance. In fact, it is ensuring, among other things, the uniformity and regularity of information transfer, in addition to the compatibility with company values, which is crucial for strategy communication itself (Aaltonen, Ikävalko, 2002).

The subject of corporate values is significant especially in the context of mergers and acquisitions when the execution of a coherent strategy is conditioned by ensuring the high level of values consistency for all business units (Gopinath, 2003). Therefore it may be claimed that in the case of structurally complex organizations, it is preferable to promote the set of 
corporate values as an element naturally cementing the executed processes and tools used.

The term of effectiveness is the second aspect under study. According to the definition of Drucker (1974), there is a difference between effectiveness and efficiency - "Efficiency is doing things right. Effectiveness is doing the right thing". Cameron (2010) remarks, on the other hand, that the effectiveness of an organization consists of a few elements:

- it accomplishes stated goals (goal model);

- it acquires needed resources (system resource model);

- it has smooth functioning and an absence of strain (internal process model);

- members are satisfied and collaboration occurs (human relations model); and

- all constituencies are at least minimally satisfied (strategic contingencies model).

Strategic performance factors influencing the effectiveness of the strategy execution process are also analysed in the above context (Palmer, 1992; Rangone, 1997). It is essential, however, to create a plan of strategy realization based on the integrated structure and interrelations between defined SPFs (Srivastava, Sushil, 2013). It is worth mentioning that organizational effectiveness is also perceived through the effective execution of strategic decisions taken by senior executives (Harrison, Pelletier 1998). Therefore the term of effectiveness is both multidimensional and ambiguous. For the purpose of this article it is assumed that the effectiveness of strategy implementation may be composed of three elements - the efficiency of actions taken (considering the pre-established objectives achievement) and overcoming external, and internal implementation barriers.

In order to achieve the assumed research objectives, the following hypothesis was formulated:

H1: There is a positive interdependency between the comprehensiveness of strategy execution and the effectiveness of implementing activities.

Moreover, auxiliary hypotheses were formulated. They are used to verify which of the strategy implementation areas has the greatest influence on the results obtained.

$\mathrm{H} 2$ : The proper operation of implementation procedures and processes affects the growth of strategy execution effectiveness.

H3: Ensuring the cohesion of corporate values has an influence on the growth of strategy execution effectiveness.

H4: Augmenting the degree to which implementation tools are used has an influence on the growth of strategy execution effectiveness. 


\section{SAMPLE AND DATA COLLECTION, RESEARCH TOOLS}

The group of respondents included managers of 69 corporate headquarters (employing over 250 people) that have been operating for at least five years and are listed among the 500 largest Polish companies in the ranking of "Polityka" magazine (101 entities) and in the "Forbes Diamonds 2013" ranking (99 companies). The first ranking takes account of sales revenues, the total revenues of the companies, the gross and net profit, as well as the number of employees. The "Diamonds" list included the companies showing the fastest increase in value. The research sample was selected based on the participation in the rankings and thereby achieving market success in the implementation of the developed strategies. The obtained results thus could be perceived as an example of good practices, and the proposals formulated on this basis could have an universal character. The grounds for undertaking research in the field of strategy implementation were based on the importance of the implementation actions and the necessity to ensure consistency between the effects of the implementation projects or the programmes and their operating results. It was especially crucial to identify the barriers that hinder the combination of the ongoing actions with their strategic implications. The results of the conducted research could be applied in practice as a base of knowledge used by the management staff to increase the flexibility and effectiveness of the strategic management process.

The study was conducted using the PAPI (Paper and Pencil Interview) technique - the quantitative survey was carried out with the use of a method based on collecting the data in the standardised way. In order to ensure the highest possible representativeness, the sample was selected using the stratified random sampling method. The primary goal of the project was to diagnose the factors that support and hinder the implementation of the strategy. The research tool focused on:

1) identification of instruments and tools used during the strategy implementation process

2) defining the procedures and systems supporting strategy execution

3) analysing the system for monitoring the effects of strategy implementation

The questions in the questionnaire were of nominal value (the respondents declared the existence of specific obstacles) and of ordinal variable nature (the respondents indicated the strength of their impact on a 5point scale). In order to test the hypotheses, Pearson's correlation coefficient was calculated. 
As stated above, the comprehensiveness of strategy implementation involves three areas:

- procedures and processes $(\mathrm{C} 1)$ - changes of organizational structure aimed at improving the strategy realization process, transferring responsibility for executive actions to leaders on different organization structure levels, and assigning a person or a specified team to be responsible for the monitoring and coordinating strategy execution processes;

- corporate values cohesion (C2) - organizing the multitasking teams' work, ensuring a smooth informal communication system, establishing unity of vision and corporate values;

- tools' usage (C3) - using BSC, strategy maps, budgeting, and scheduling tasks.

The effectiveness of strategy execution was defined by:

- the efficacy of realized activities (E1) - the level of assumed strategic objectives achievement;

- eliminating internal barriers (E2), which included the following:

- the area of strategy content (E2a) - unclearly stated assumptions, internal incoherence (of vision, objectives, schedule, budget), inflexibility and invariability of the solutions accepted in the strategy;

- the area of employees' engagement (E2b) - the lack of connection between operating and strategic activities, lack of management support, the absence of employees' identification with the executed strategy;

- the area of processes and resources (E2c) - insufficient financial sources for the strategy execution, lack of developed methods for action in critical situations, lack of or inappropriate motivators supporting the realization of strategic goals.

- eliminating external barriers (E3) such as - dynamism of changes occurring in the environment which force the frequent modification of the implemented strategy, information and data overload, slowing down the process of implementing key decisions, the necessity of creating a monitoring system for the environment of the company.

\section{RESEARCH RESULTS AND DISCUSSION}

The first stage of the research was the calculation of the average degrees of comprehensiveness and executed strategy effectiveness for each surveyed entity. Subsequently Pearson's correlation coefficient (level) for the entire examined sample was calculated. Table 1 indicates the results of the research: 
Table 1

The correlation between comprehensiveness and effectiveness of the strategy execution

\begin{tabular}{l|c}
\hline & Result \\
\hline Pearson correlation & 0.468 \\
\hline Dual significance & 0.002 \\
\hline $\mathrm{N}$ & 69 \\
\hline
\end{tabular}

Source: own research

As the analysis of the results shows, there is a significant positive correlation between the comprehensiveness of the implementation activities and the effectiveness of strategy execution. This means that the higher the comprehensiveness of the activities which ensure a coherent and comprehensive perspective for the organization of strategy implementation process, the higher the degree of the process effectiveness. This could be a hint for managers who want to ensure the expected results of the strategic management process. It is therefore necessary to perceive the strategy execution as a set of deliberate and systematic actions, that are designed using a holistic perspective. This makes it possible to eliminate potential conflicts between the components of this process, as well as ensuring the effective implementation of each aspect, both separately and in combination with each other. It seems that companies having a higher strategic awareness of interrelations between elements of the strategy execution process are more effective in their undertakings.

Therefore, the hypothesis (H1) may besupported. Further results analysis, however, indicated some differences in the interdependencies between particular aspects of the variables examined. The results are presented in Table 2.

Table 2

Correlations between the aspects of comprehensiveness and the effectiveness of strategy implementation

\begin{tabular}{l|c|c|c}
\hline & $\mathrm{C} 1$ & $\mathrm{C} 2$ & $\mathrm{C} 3$ \\
\hline Pearson correlation & 0.284 & 0.457 & 0.173 \\
\hline Dual significance & 0.038 & 0.000 & 0.017 \\
\hline $\mathrm{N}$ & 69 & 69 & 69 \\
\hline
\end{tabular}

Source: own research 
The results show that the highest correlation level was obtained in the case of the second area (0.457). Ensuring the cohesion of corporate values most strongly influences the effectiveness of the realized strategies. Hypothesis (H3) can therefore be supported. The cohesion of corporate values and undertaken activities ensures their higher transparency and facilitates the communication process. This concerns both the conceptual stage - the creation of the strategy, as well as its implementation. Thanks to that, the level of assumed objectives is higher and the achieved results are more satisfying. There is no doubt that this is a difficult task, which is related to the intangible nature of efforts necessary to integrate corporate values with other aspects of the strategy and the transposition into actions with a specific measurability. This could be an important implication for managers who should consider this issue during the designing stage of the strategy execution process, and while supervising its results. The research results confirmed those obtained by other authors, showing that it is an integral element linking operational activities with the expected results (van Marrewijk, 2004).

A slightly lower level of correlation was obtained in the case of the $\mathrm{H} 2$ hypothesis, in which the result was 0.284 . The organization of an efficacious system of procedures and processes promotes the growth of strategy execution effectiveness. In particular, this refers to the issue of the appropriate usage of the available resources, including carrying out changes in the organizational structure supporting its effectiveness. This is confirmed by the results of research conducted by Hülsmann and Grappa (2005).

The lowest level of correlation was found in the case of implementation tools usage (0.173), which may be an unexpected result as many studies point out that the tools are mentioned amongst the most powerful elements improving the process of strategy execution. Nevertheless, the positive character of this relationship indicates that the higher degree of their use, the higher the effectiveness of strategy execution. Although the described relation is too weak to draw unequivocal conclusions, it is worth mentioning that it is one of the significant components of strategy execution. Therefore there are many factors which influence the results of this process, with implementation tools not taking a leading role among them. Their usage, however, is of significance not only in the context of introducing improvement to the processes in progress, but most of all it gives them a more formal character which results in the improvement of strategy communication and execution. 
The relations between particular aspects of execution effectiveness and comprehensiveness of the strategy were also examined. The results are shown in Table 3.

Table 3

The correlation between the aspects of strategy execution effectiveness and its comprehensiveness

\begin{tabular}{l|c|c|c|c|c}
\hline & E1 & E2a & E2b & E2c & E3 \\
\hline Pearson correlation & 0.278 & 0.286 & 0.237 & 0.295 & 0.298 \\
\hline Dual significance & 0.032 & 0.16 & 0.038 & 0.026 & 0.106 \\
\hline $\mathrm{N}$ & 63 & 69 & 69 & 69 & 69 \\
\hline
\end{tabular}

Source: own research

The results indicate that there is a similar level of relationship between all the elements influencing the effectiveness of strategy execution and its comprehensiveness.

This means that eliminating internal barriers makes the strategy execution process more coherent and extensive. The same applies to the elimination of external obstacles which enables greater focus on the course of implementation processes according to the adopted assumptions. A positive relationship between the strategic objectives' realization and the comprehensiveness of strategy execution may also be indicated. This signifies the fact that achieving determined strategic objectives translates into augmenting the cohesion of corporate values, as well as the processes or tools used. Managers should therefore treat all three aspects of the strategy effectiveness as equivalent and equally monitor the processes associated with them. Excessive focusing on one element (usually elimination of internal barriers) may be in fact insufficient to ensure the desired results.

\section{CONCLUSION}

The results obtained in the study indicate that there is a strong positive relationship between the comprehensiveness of the strategy execution process and its effectiveness. Thus, increasing the scope of the undertaken implementing activities and ensuring their coherence (in the area of corporate values, tools and processes) results in the growth of their effectiveness measured by the ability to overcome internal and external implementation barriers, as well as the successful execution of the strategic 
objectives. It is worth emphasizing that the analysis of partial results proved that fragmented aspects of the strategy execution process themselves have a weaker influence on its effectiveness than their combination. Organizations which successfully realize the process of strategy implementation, while taking into account its various aspects, have a bigger chance of achieving the planned results than companies without this awareness, focusing exclusively on one of its elements, for instance the usage of tools. It appears that the process of strategy execution ought to be a sequence of well thought-out, systematic proceedings, and not partial or incidental activities.

The main limitation to the study is the subjectivity of the answers provided. It could be also necessary to analyse if the defined strategy comprehensiveness and effectiveness should not be defined using different elements. This is worth examining in greater depth with further research.

\section{REFERENCES}

Aaltonen, P., Ikävalko, H., Implementing Strategies Successfully, "Integrating Manufacturing Systems", Vol 13, No. 6, pp. 415-418, 2002.

Beer, M., Nohria, N., Cracking the Code of Change, "Harvard Business Review", No. 78, pp. 133-141, 2000.

Bertrand, M., Schoar, A., Managing with Style: The Effect of Managers on Firm Polices, "Quarterly Journal of Economics", No. 118, pp. 1169-1208, 2003.

Bossidy, L., Charan, R., Execution: The Discipline of Getting Things Done. Random House Business Books, London, 2002.

Bourguignon, A., Malleret, V., Norreklit, H., The American Balanced Scorecard versus the French Tableau de Bord: The Ideological Dimension, "Management Accounting Research", Vol. 15, pp. 107-134, 2004.

Cameron, K. S. (2010), Organizational Effectiveness. Edward Elgar Publishing, Cheltenham 2010.

Carlopio, J., Harvey, M., The Development of Social Psychological Model of Strategy Implementation, "International Journal of Management", Vol. 29, No. 3, pp. 76-78, 2012.

Cheng, M., Humphreys, K., The Differential Improvement Effects of the Strategy Map and Scorecard Perspectives on Manager's Strategic Judgments, "The Accounting Review", Vol. 87, No. 3, pp. 899-924, 2012.

Coon, B., Wolf, S., The Alchemy of Strategy Execution, Employment Relations Today, "Wiley", pp. 29-30, 2005.

Dandira, M., Involvement of Implementers: Missing Element in Strategy Formulation, "Business Strategy Series", Vol. 12, No. 1, p. 33, 2011.

Drucker, P. F., Management: Tasks, Responsibilities, Practices. Harper \& Row, New York, NY 1974. 
Free, C., Qu, S., The Use of Graphics in Promoting Management Ideas: An Analysis of the Balanced Scorecard, 1992-2010, "Journal of Accounting \& Organizational Change", Vol. 7, No. 2, pp. 158-189, 2011.

Fredrickson, W., Mitchell, T., Strategic Decision Processes: Comprehensiveness and Performance in an Industry with an Unstable Environment, "Academy of Management Journal", Vol. 27, pp. 399-423, 1984.

González, J. M., Calderón, M. A., González, J. L., The Alignment of Manager's Mental Models with the Balanced Scorecard Strategy Map, "Total Quality Management", Vol. 23, No. 5, pp. 624-625, 2012.

Gopinath, C., When Acquisitions Go Awry: Pitfalls in Executing Corporate Strategy, "Journal of Business Strategy", Vol. 24, No. 5, pp. 22-26, 2003.

Gibbs, C., Keys to Strategy Implementation, "Insights in Strategic Management", p. 9, 2005.

Hao, Q., Kasper, H., Muehlbacher, J., How Does Organizational Structure Influence Performance through Learning and Innovation in Austria and China, "Chinese Management Studies", Vol. 6, No. 1, pp. 36-52, 2012.

Harrison, E., Pelletier M., Foundations of Strategic Decision Effectiveness, "Management Decision”, Vol. 36, Issue 3, pp. 147-159, 1998.

Higgins, J., The Eight 'S' of Successful Strategy Execution, "Journal of Change Management", Vol. 5, No. 1, pp. 3-13, 2005.

Hrebiniak, L., Obstacles to Effective Strategy Implementation, "Organizational Dynamics", Vol. 35, No. 1, pp. 12-31, 2006.

Hrebiniak, L., Making Strategy Work: Overcoming the Obstacles to Effective Execution, "Ivey Business Journal Online", Vol. 72, No. 2, pp. 1-6, 2008.

Hülsmann, M., Grapp, J., Recursivity and Dilemmas of a Sustainable Strategy ManagementNew Visions for a Corporate Balancing Efficiency and Sustainability by Autonomous Cooperation in Decision Making Processes [in:] Foresight Management in Corporations and Public Organizations - New Visions for Sustainability, pp. 1-15, 2005.

Judge, T. A., Piccolo, R. F., Transformational and Transactional Leadership: A Metaanalytic Test of Their Relative Validity, "Journal of Applied Psychology", No. 89, pp. 755-768, 2004.

Latemore, G., Organizational Effectiveness, "Leadership \& Organization Development Journal", Vol. 34, Issue 1, p. 98, 2013.

Marrewijk, M. van, A Value-based Approach to Organization Types: Toward a Coherent Set of Stakeholder-oriented Management Tools, "Journal of Business Ethics", Vol. 55, Issue 2, pp. 147-158, 2004.

Mezger, S., Violani, M., Seven Basic Strategic Missteps and How to Avoid Them, "Strategy \& Leadership", 39(6), p. 24, 2011.

O'Reilly, C., Caldwell, D., Chatman, J., Lapiz, M., Self W., How Leadership Matters: The Effects of Leaders' Alignment on Strategy Implementation, "The Leadership Quarterly", No. 21, pp. 104-113, 2010.

Palmer, R. J., Strategic Goals and Objectives and the Design of Strategic Management Accounting Systems, “Advances in Management Accounting”, Vol. 1, pp. 179-204, 1992.

Rangone, A., Linking Organizational Effectiveness, Key Success Factors and Performance Measures: An Analytical Framework, "Management Accounting Research", Vol. 8, No. 2, pp. 207-219, 1997. 
Rapert, M., Velliquette, A., Garretson, J., The Strategic Implementation Process: Evoking Strategic Consensus through Communication, "Journal of Business Research", No. 55, No. 4, pp. 301-310, 2002.

Raps, A., Implementing Strategy, “Strategic Finance”, No. 85, pp. 48-53, 2004.

Robbin, S., DeCenzo, D., Fundamentals of Management: Essential Concepts and Applications. Prentice Hall, Upper Saddle River, pp. 156-160, 2005.

Saunders, M., Mann, R., Implementing Strategic Initiatives: A Framework of Leading Practices, "International Journal of Operations \& Production Management", Vol. 28, No. 11, pp. 1104-1106, 2008.

Schaap, J., Toward Strategy Implementation: An Empirical Study of the Role of Senior-Level Leaders in the Nevada Gaming Industry, "UNLV Gaming Research \& Review Journal", Vol. 10, Issue 2, pp. 13-37, 2006.

Sharma, M., Bhagwat, R., Dangayach, G., Practice of Performance Measurement: Experience from Indian SMEs, "International Journal of Globalization and Small Business", Vol. 1, No. 2, pp. 183-213, 2005.

Srivastava, A., Sushil, Modeling Strategic Performance Factors for Effective Strategy Execution, "International Journal of Productivity and Performance Management", Vol. 62, Issue 6, pp. 554-582, 2013.

Ramsey, R., Strategic Management: Formulation, Implementation, and Control in a Dynamic Environment, "International Journal of Commerce and Management", Vol. 20, Issue 2, pp. 188-189, 2010.

Thompson, K., Mathys, N., The Aligned Balanced Scorecard: An Improved Tool for Building High Performance Organizations, "Organizational Dynamics”, Vol. 37, No. 4, pp. 378-93, 2008.

Received: June 2015, revised: October 2015

Acknowledgments: The project was financed with funds from The National Science Centre, the project number 2014/13/D/HS4/01425 and DEC-2011/03/B/HS4/04247. 